\title{
Effect of deep cervical flexors training on neck proprioception, pain, muscle strength and dizziness in patients with cervical spondylosis: A randomized controlled trial
}

Marwa Shafiek Mustafa Saleh ${ }^{1 *}$, Nagwa Ibrahim Rehab ${ }^{2}$ and Moussa Abdel Fattah Sharaf ${ }^{3}$

*Correspondence: Marwa_shafiek2000@yahoo.com

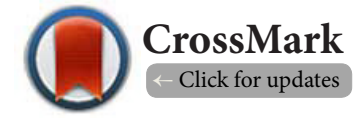

'Department of Basic Science for Physical Therapy, Faculty of Physical Therapy, Cairo University, Egypt.

2,3Physical Therapy Department for Neuromuscular Disorders \& its Surgery, Faculty of Physical Therapy, Cairo University, Egypt.

\begin{abstract}
Background: Patients with cervical spondylosis are commonly suffering from neck pain and dizziness due to disturbance in cervical propriocetion. So, inhibiting the causes and improving proprioception might be a key for a positive treatment effect .

Purpose: This study aimed to evaluate the effect of deep cervical flexors (DCFs) training on neck proprioception, pain, muscle strength and dizziness in patients with cervical spondylosis.

Methods: Forty patients with cervical spondylosis suffering from neck pain and dizziness were chosen from Out-Patient Clinic, Faculty of Physical Therapy, Cairo University to participate in this study. They were randomly divided into two equal groups. The study group (A): received DCFs training plus traditional physical therapy (hot backs, TENS and cervical proprioceptive training). The control group (B): received traditional physical therapy only. Outcome measures included head repositioning accuracy (HRA), severity of pain, DCFs strength, severity of dizziness and dizziness handicap inventory (DHI). Measures were assessed for all patients in both groups before and after 6 weeks of treatment program (3 sessions/week).

Results: There was a significant improvement for all of the measured variables after treatment in each group, and there was a significant difference between the two groups in favor of the study group (A) for all of the measured variables including HRA for right rotation $(\mathrm{p}=0.001)$, HRA for left rotation $(\mathrm{p}=0.001)$, severity of pain $(p=0.003)$, DCFs strength $(p=0.001)$, severity of dizziness $(p=0.01)$ and DHI $(p=0.001)$.
\end{abstract}

Conclusions: The study findings indicate that DCFs training was more effective than traditional physical therapy for improving neck proprioception, pain, muscle strength and dizziness in patients with cervical spondylosis. Hence, it is recommended in the rehabilitation of patients with cervical spondylosis.

Keywords: Deep cervical flexors training, Neck Proprioception, Neck pain, Deep cervical flexors strength, Dizziness, Cervical spondylosis

\section{Introduction}

Cervical spondylosis is a common degenerative condition of the cervical spine in the general population, which occurs mostly in the fourth and fifth decades of life [1]. It is considered one of the most common causes of neck pain leading to decreased quality of life and socioeconomic damages such as medical expenses [2] and a major cause of poor balance and dizziness associated with spinal degeneration [3]. 
It has been reported that, patients with cervical spondylosis have demonstrated altered proprioception [4]. These impairment in cervical proprioceptive inputs have been attributed to neck pain and altered input from cervical afferents particularly muscle spindle. Muscle spindle are accepted as being the primary cervical receptors responsible for position sense and are coupled to supplementary afferent input from the cutaneous and joint receptors [4-6]. So, improvement of muscle spindle function is translated to improved cervical proprioception.

With regard to cervical muscles, the high density concentrations of muscle spindles have been identified in the suboccipital muscles and the deeper cervical muscles [4]. It has been theorized that when cervical muscle performance is impaired, the balance between the stabilizers on the posterior aspect of the neck and the Deep Cervical Flexors (DCFs) will be disrupted, resulting in loss of proper alignment and posture, which is then likely to contribute to cervical impairment and neck pain [7]. So, for controlling neck posture and relieving pain which in turn leads to improvement of prorioception and dizziness, typically specific proprioceptive training regimes are designed to target the deep suboccipital muscles, such programs include gaze stability exercises, eye-head coordination and/or practice of relocation of the head on the trunk $[8,9]$.

Also, DCFs training which aims to enhance activation of the DCFs and restore coordination between the deep and superficial cervical flexors, is one form of exercise that has been advocated for addressing impaired neuromuscular control of the cervical flexors [10]. Clinical trials examining the effectiveness of this exercise regime have demonstrated positive outcomes in terms of decrease in neck pain and disability, improvement in sitting posture, enhanced neuromuscular control of the cervical flexors in patients with chronic neck pain [10-14], and also improved proprioceptive acuity of the neck, indicating that proprioception can be enhanced with specific exercise [11].

On the light of the previous research studies, sensorimotor proprioceptive disturbances in the cervical spine might be an important factor in the maintenance, recurrence, or progression of various symptoms in patients with neck pain. Thus, addressing these deficits are likely to be an important step towards better management of patients with cervical spondylosis. So, the current randomized controlled study which is first of its kind was conducting to investigate the effect of DCFs training on neck proprioception, pain, muscle strength and dizziness in patients with cervical spondylosis.

\section{Materials and methods}

This randomized experimental trial was conducted at the OutPatient Clinic of Faculty of Physical Therapy, Cairo University from January to April 2018. The study protocol was explained in details for each patient before the initial assessment and enrollment in the study and all patients signed an institutionally approved informed consent form which was approved by the Ethics Committee of the Faculty of Physical Therapy, Cairo University (P.T.REC/012/001900).

\section{Participants}

A total of 54 patients with cervical spondylosis based on careful clinical assessment and radiological investigations by $X$ rays were initially screened, and after the screening process 40 patients were eligible to participate in this study as shown in Figure 1. Patients were eligible to participate in this study

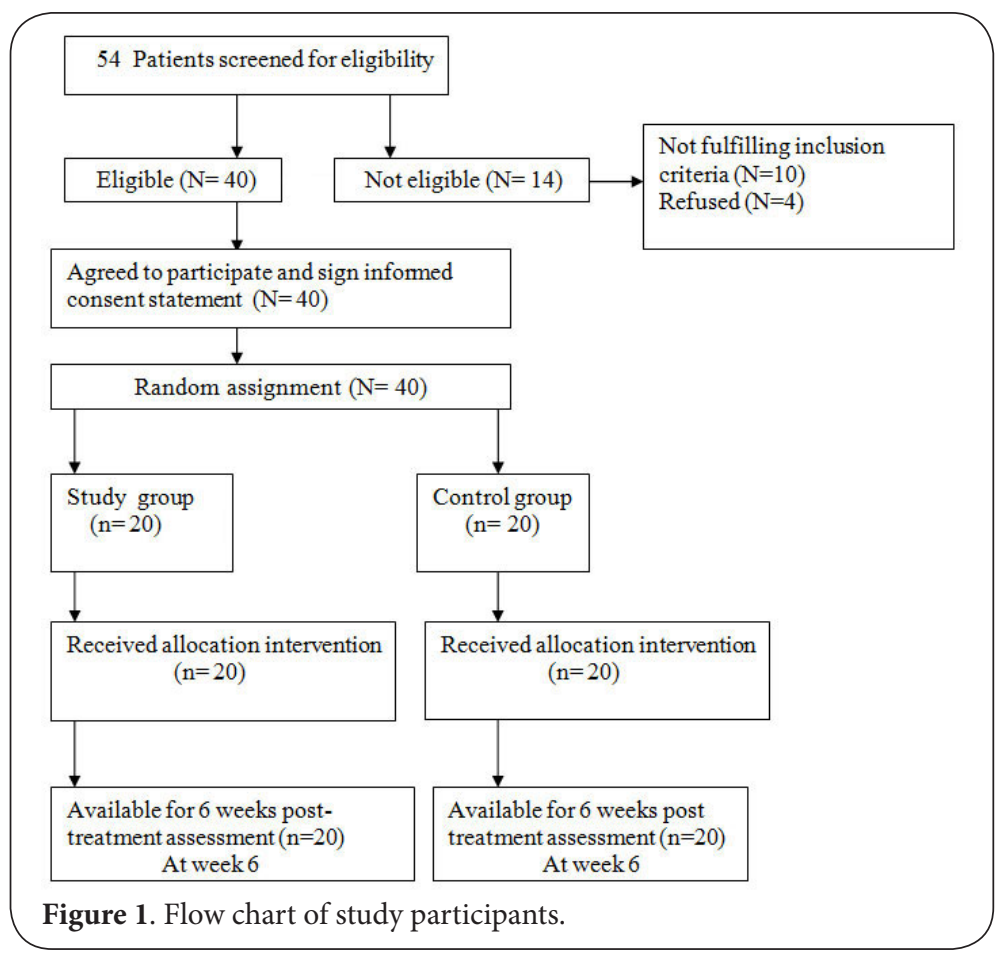


if they had age ranging from 45 to 55 years, concurrent neck pain and dizziness for more than six months, dizziness related to either position or movement of the neck, dizziness described as imbalance or unsteadiness (not rotatory vertigo) and moderate disability score on the Dizziness Handicap Inventory (DHI) (31-60 points) [15]. While patients were excluded if they had cervical myelopathy or radiculopathy, tumor or infection involving cervical spine, history of cervical injury or trauma, poor hearing or vision, congenital anomalies involving the cervical spine, any neurologic disease (e.g, cerebellar disorders, multiple sclerosis, Parkinson's disease, syringomyelia), benign positional vertigo, Meniere's diseases, acute peripheral vestibulopathy, chronic sinusitis or pain and dizziness due to whiplash injury.

Patients were randomly assigned to the study group $A(n=20)$ or the control group $B(n=20)$ by an independent person who picked one of the sealed envelopes, which contained numbers chosen by random number generator. Randomization was restricted to permuted blocks of different size to ensure that equal numbers were allocated to each group. Each random permuted block was of consecutively numbered, sealed, opaque envelopes and these were stored in a locked drawer until required. As each participant formally entered the trial, the researcher opened the next envelope in the sequence in the presence of the patient.

Patients in both groups received the same traditional physical therapy treatment including hot backs, Trancutaneous Electrical Nerve Stimulation (TENS) and cervical proprioceptive training, 3 days per week for six weeks. The study group additionally received DCFs training using Pressure Biofeedback Unit (PBU).

\section{Examination}

All of the following assessments were done to all patients in both groups (A) and (B) before and after 6 weeks of treatment program by outcome assessor who was not masked during the study.

\section{Measurement of cervical proprioception}

Cervicocephalic kinesthetic sensibility was assessed by measuring the Head Repositioning Accuracy (HRA) using the Cervical Range of Motion (CROM) device. The CROM device is a type of goniometer designed specifically for the cervical spine and was used to measure cervical ROM [16]. It consists of a plastic frame that is mounted over the subject's nose bridge and ears and secured to the head by a felcro strap. Three independent inclinometers attached to the frame and arranged orthogonally to one another indicate the subject's cervical ROM. The CROM device has good criterion validity ( $r$ $=0.89-0.99)$ and reliability $($ ICC $=0.92-0.96)$ [17]. For testing, the subjects were asked to sit upright in a comfortable position, their feet flat on the ground and their head in a neutral position. The participants (blindfolded) started with their head in the Neutral Head Position (NHP) and were asked to actively move to the midpoint of their maximum rotation range, which was called the "target position". After $5 \mathrm{sec}$, the patients return their head to NHP, then they were asked to rotate their head to the target position. The difference between the target position and the achieved position was recorded 3 times for both right and left rotation and the average taken for each direction of rotation movement according to Reid et al. [18].

\section{Measurement of pain intensity}

Severity of cervical pain was measured using Visual Analogue Scale (VAS). The VAS is a horizontal continuous scale, $10 \mathrm{~cm}$ in length, ended with two verbal pain descriptors on either end one is "no pain" (score of 0 ) and "pain as bad as it could be" or "worst imaginable pain"(score of 10) on other end [19]. The patients were asked to point the suitable score on the line that represent their pain intensity. Visual analogue scale is reliable and valid to measure pain intensity in neck pain [20].

\section{Measurement of deep cervical flexors strength}

Strength of DCFs were measured using PBU during the CranioCervical Flexion Test (CCFT). The PBU provides the feedback and direction to the patient to perform the required five stages of the test. The CCFT is performed with the patient in crock lying with the cervical spine was kept in a neutral position as described by Chiu et al. [21]. The PBU was inflated to a baseline of $20 \mathrm{mmHg}$ after placing it between the plinth and the posterior aspect of the neck just below the occiput. Subjects were given practice sessions to learn the CCFT with the PBU, and they were instructed to relax the neck musculature and to concentrate on permitting a gentle and slowly head nodding movement, and to avoid head lift for reducing the recruitment of superficial flexors. During the practice phase of the CCFT, the examiner observed and corrected any substitutions to ensure performance of a correct test and any recruitment of superficial neck flexor muscles is discouraged by the examiner by verbal feedback. Each patient had to perform the neck Cranio-Cervical Flexion (CCF) movement at 5 different pressure levels $(22,24,26,28$ and $30 \mathrm{mmHg}$ ) with $10 \mathrm{sec}$ hold at each level and $30 \mathrm{sec}$ rest between each level. The testing procedure was terminated if subject could not hold $10 \mathrm{sec}$ at specific pressure level or if the maximum level of $30 \mathrm{mmHg}$ was achieved. The maximum pressure level achieved (activation score) with 10 sec hold was recorded for analysis purpose.

\section{Measurement of dizziness intensity}

The severity of dizziness (an average level over the previous week) was measured with a $100 \mathrm{~mm}$ horizontal VAS, which has been used successfully to measure dizziness in a previous study [22].

\section{Measurement of disabilities caused by dizziness}

Disability caused by dizziness was measured with $\mathrm{DHI}$. This is a health status measure questionnaire composed of 25 questions specifically designed to assess the quality of life 
using three subscales evaluating the impact of dizziness on the functional (nine), emotional (nine) and physical aspects (seven) of everyday life. For each question, patients respond "yes," "sometimes," or "no," corresponding to four, two, or zero points, respectively. The highest possible score is 100 , indicating maximum self-perceived handicap [23]. The DHI has been shown to be a highly reliable and responsive tool [23-25].

\section{Treatment}

The patients in both groups received the same traditional physical therapy treatment including hot packs, TENS and cervical proprioceptive training 3 times a week for six weeks. The patient was instructed to lie prone and hot packs were applied on the neck for 15 minutes. Then, TENS was administered at a frequency of $80 \mathrm{~Hz}$ with 10-30 mA intensity for 20 minutes. Four surface electrodes, $5 \times 5 \mathrm{~cm}$ each, were placed over the painful area in the neck region [26]. TENS was delivered using Intelect Advanced (REF2773MS; Chattanooga: Mexico).

\section{Cervical proprioceptive training}

Patients trained cervical proprioception following the protocol described by Revel et al. [8]. Exercises included oculomotor exercises and eye-head coordination exercises. Oculomotor exercises were progressed through several stages. First, eye movement following a target located at a comfortable distance was practiced with the head stationary, progressing to movements of the head with visual fixation on a target (gaze stability). Eye-head coordination exercises started with rotation of the eyes and head to the same side, in both left and right directions. Subsequently, the patient practiced following a target with the eyes first, followed by the head, ensuring that they maintained focus on the target. As a further progression, the eyes moved first, and then the head, to look between 2 targets positioned horizontally or vertically, and finally, the eyes and head rotated in opposite directions, both left and right. All these exercises were further progressed by increasing the speed and range of movements and/or alteration of the visual target.

The study group received the same program of the control group in addition to DCFs training 3 times a week for six weeks.

\section{Deep cervical flexors training}

Low load training of the CCFs followed the protocol described by Jull et al. [27]. This exercise specifically targets the DCFs (longus capitis and longus colli), while aiming to minimize the activation of the superficial cervical flexors (sternocleidomastoid and anterior scalene). Initially, from a supine lying position the patients were taught to perform the CCF movement slowly and in a controlled manner, with the head and neck in a neutral position. Once the correct CCF motion was achieved, patients began to hold progressively increasing ranges of CCF using PBU (Stabilizer TM Chattanooga Group Inc., Tennessee, USA), which placed behind the neck just next to the occiput and was inflated up to a baseline pressure of
$20 \mathrm{mmHg}$. The patients performed CCF to sequentially reach 5 pressure targets in $2 \mathrm{mmHg}$ increments from a baseline of $20 \mathrm{mmHg}$ to the final level of $30 \mathrm{mmHg}$. For each target level, the patients were instructed to maintain the contraction for $10 \mathrm{sec}$ for 10 repetitions with brief rest periods between each contraction ( 3-5 sec). Once a set of 10 repetitions of $10 \mathrm{sec}$ was achieved at one target level, the exercise was progressed to train at the next target level up to the final target level at $30 \mathrm{mmHg}$.

\section{Data analysis}

Descriptive analysis, including mean and standard deviation, were performed for all variables. t-test were conducted for comparison of subject characteristics between both groups. Chi- squared test was used for comparison of sex distribution between groups. Normal distribution of data was checked using the Shapiro-Wilk test for all variables. Unpaired t-test was conducted to compare the mean values of HRA, pain intensity, DCFs strength, severity of dizziness and DHI between the study and control groups. Paired $t$ test was conducted for comparison before and after treatment in each group. The level of significance for all statistical tests was set at $p<0.05$. Statistical analysis was conducted through the statistical package for social studies (SPSS) version 19 for windows (IBM SPSS, Chicago, IL, USA).

\section{Results}

\section{Subject characteristics}

As shown in Table 1, there was no significant difference between both groups in the mean age, weight, height and body mass index $(p<0.05)$. Also, There was no significant difference between both groups in the duration of dizziness $(p=0.59)$, and sex distribution $(p=0.51)$.

\section{Comparison of pre and post treatment for both study and control groups}

As shown in Tables 2 and $\mathbf{3}$, there were significant differences between pre and post treatment in all measured variables in both study and control groups. As, right and left HRA, pain intensity, severity of dizziness and DHI showed significant decrease post treatment compared with pre treatment $(p=0.001)$. Also, there was a significant increase in the DCFs strength post treatment compared with pre treatment $(p=0.001)$.

\section{Comparison of pre and post treatment between study and control groups}

As shown in Table 4, there was no significant difference between the study and control groups in all measured variables pre-treatment $(p>0.05)$. While, Post treatment there was a significant decrease in right and left HRA, pain intensity, severity of dizziness and $\mathrm{DH}$ of the study group compared with that of control group ( $p>0.01$ ). Also, there was a significant increase in the DCFs strength of the study group compared with that of control group $(p=0.001)$. 
Table 1. Comparison of the mean age, weight, height, BMI, duration of dizziness and sex distribution between study and control groups.

\begin{tabular}{lccccc}
\hline & $\begin{array}{c}\text { Study group } \\
(\mathbf{n = 2 0})\end{array}$ & $\begin{array}{c}\text { Control group } \\
(\mathbf{n = 2 0})\end{array}$ & t- value & p- value & Significance \\
\hline Age (yrs.) & $47.9 \pm 2.77$ & $48.65 \pm 2.73$ & -0.86 & 0.39 & $\mathrm{NS}$ \\
Weight (kg) & $73.85 \pm 8.96$ & $76.1 \pm 9.07$ & -0.78 & 0.43 & $\mathrm{NS}$ \\
Height (cm) & $164.1 \pm 6.52$ & $167.45 \pm 7.1$ & -1.55 & 0.12 & $\mathrm{NS}$ \\
BMI (kg/m $)$ & $27.46 \pm 3.25$ & $27.11 \pm 2.42$ & 0.37 & 0.7 & $\mathrm{NS}$ \\
$\begin{array}{l}\text { Duration of dizziness } \\
\text { (weeks) }\end{array}$ & $17.55 \pm 4.68$ & $16.75 \pm 4.75$ & 0.53 & 0.59 & $\mathrm{NS}$ \\
Males/Females & $7 / 13$ & $9 / 11$ & $\left(\boldsymbol{\chi}^{2}=0.41\right)$ & 0.51 & $\mathrm{NS}$ \\
\hline
\end{tabular}

Data are expressed as mean $\pm \mathrm{SD}$; \#=unpaired t-test; $\chi 2$, Chi squared value; $N S=p>0.05=$ non-significant; BMI: Body Mass Index

Table 2. Comparison between mean values of each measured variable before and after treatment for the study group.

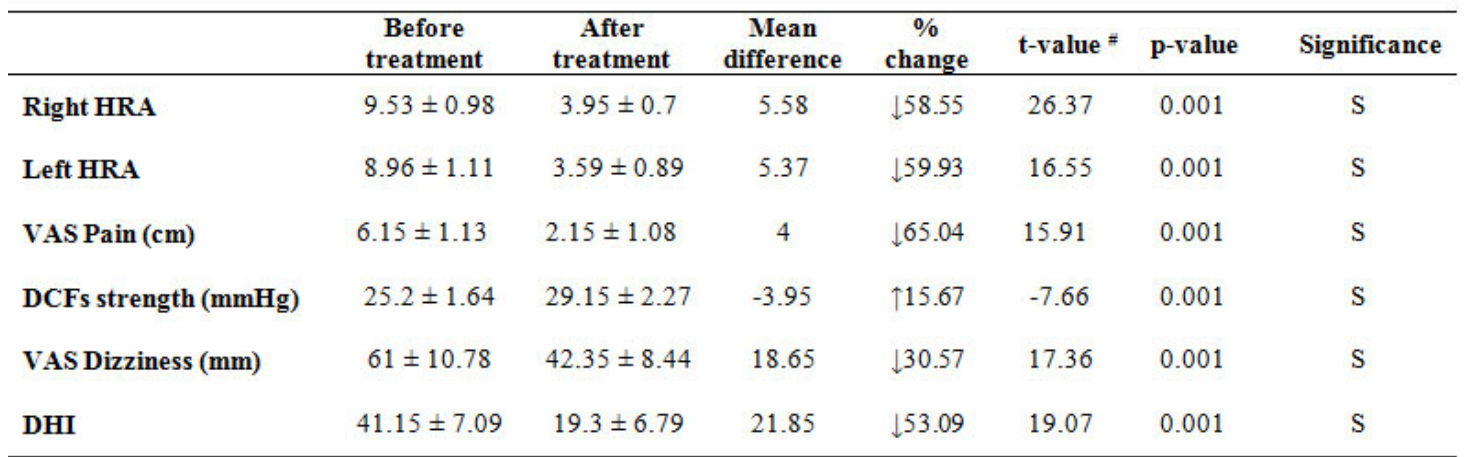

Data are expressed as mean $\pm \mathrm{SD}$; $=$ paired t-test; $\mathrm{S}=\mathrm{p}>0.05=$ significant; HRA: Head Repositioning Accuracy; VAS: Visual Analogue Scale; DCFs: Deep Cervical Flexors; DHI: Dizziness Handicap Inventory

Table 3. Comparison between mean values of each measured variable before and after treatment for the control group.

\begin{tabular}{lcccccc}
\hline & $\begin{array}{c}\text { Before } \\
\text { treatment }\end{array}$ & $\begin{array}{c}\text { After } \\
\text { treatment }\end{array}$ & $\begin{array}{c}\text { Mean } \\
\text { difference }\end{array}$ & \% change & t-value $^{\#}$ p-value & Significance \\
\hline Right HRA & $9.1 \pm 1.25$ & $6.75 \pm 0.81$ & 2.35 & $\downarrow 25.82$ & 7.71 & 0.001 \\
Left HRA & $9.21 \pm 0.58$ & $7.65 \pm 0.8$ & 1.56 & $\downarrow 16.93$ & 7.91 & 0.001 \\
VAS Pain (cm) & $6 \pm 1.25$ & $3.35 \pm 1.3$ & 2.65 & $\downarrow 44.16$ & 8.78 & 0.001 \\
DCFs strength (mmHg) & $25 \pm 1.89$ & $26.6 \pm 2.06$ & -1.6 & $\uparrow 6.4$ & -6.83 & 0.001 \\
VAS Dizziness (mm) & $61.05 \pm 11.29$ & $48.8 \pm 7.88$ & 12.25 & $\downarrow 20.06$ & 7.03 & 0.001 \\
DHI & $41.3 \pm 9.25$ & $33.55 \pm 6.71$ & 7.75 & $\downarrow 18.76$ & 4.96 & 0.001 \\
\hline
\end{tabular}

Data are expressed as mean $\pm \mathrm{SD}$; \#=paired t-test; $\mathrm{S}=\mathrm{p}>0.05=$ significant; HRA: Head Repositioning Accuracy; VAS: Visual Analogue Scale; DCFs: Deep Cervical Flexors; DHI: Dizziness Handicap Inventory

\section{Discussion}

Disturbance of afferent input from proprioceptors of the neck in patients with cervical spondylosis, leads to a sensory mis- match between cervical, visual and vestibular inputs to the sensorimotor control system and has been associated with objective deficits in proprioception $[4,28]$. Because improving 
Table 4. Comparison between study and control groups on each measured variable before and after treatment.

\begin{tabular}{|c|c|c|c|c|c|}
\hline & $\begin{array}{c}\text { Study group } \\
(\mathrm{n}=\mathbf{2 0})\end{array}$ & $\begin{array}{c}\text { Control group } \\
(\mathrm{n}=\mathbf{2 0})\end{array}$ & t- value $\#$ & p-value & Significance \\
\hline \multicolumn{6}{|l|}{ Before treatment } \\
\hline Right HRA & $9.53 \pm 0.98$ & $9.1 \pm 1.25$ & 1.21 & 0.23 & NS \\
\hline Left HRA & $8.96 \pm 1.11$ & $9.21 \pm 0.58$ & -0.88 & 0.38 & NS \\
\hline VAS Pain (cm) & $6.15 \pm 1.13$ & $6 \pm 1.25$ & 0.39 & 0.69 & NS \\
\hline DCFs strength (mmHg) & $25.2 \pm 1.64$ & $25 \pm 1.89$ & 0.35 & 0.72 & NS \\
\hline VAS Dizziness (mm) & $61 \pm 10.78$ & $61.05 \pm 11.29$ & -0.01 & 0.98 & NS \\
\hline DHI & $41.15 \pm 7.09$ & $41.3 \pm 9.25$ & -0.05 & 0.95 & NS \\
\hline \multicolumn{6}{|l|}{ After treatment } \\
\hline Right HRA & $3.95 \pm 0.7$ & $6.75 \pm 0.81$ & -11.6 & 0.001 & $\mathrm{~S}$ \\
\hline Left HRA & $3.59 \pm 0.89$ & $7.65 \pm 0.8$ & -15.08 & 0.001 & $\mathrm{~S}$ \\
\hline VAS Pain (cm) & $2.15 \pm 1.08$ & $3.35 \pm 1.3$ & -3.15 & 0.003 & $\mathrm{~s}$ \\
\hline DCFs strength (mmHg) & $29.15 \pm 2.27$ & $26.6 \pm 2.06$ & 3.71 & 0.001 & $\mathrm{~s}$ \\
\hline VAS Dizziness (mm) & $42.35 \pm 8.44$ & $48.8 \pm 7.88$ & -2.49 & 0.01 & $\mathrm{~s}$ \\
\hline DHI & $19.3 \pm 6.79$ & $33.55 \pm 6.71$ & -6.66 & 0.001 & $\mathrm{~S}$ \\
\hline
\end{tabular}

Data are expressed as mean \pm SD; \#=unpaired t-test; NS=p>0.05=non-significant; $\mathrm{S}=\mathrm{p}>0.05=$ significant; HRA: Head Repositioning Accuracy; DCFs: Deep Cervical Flexors; VAS: Visual Analogue Scale; DHI: Dizziness Handicap Inventory

proprioception might be a key for a positive treatment effect [28], and high density concentrations of muscle spindles have been identified in the suboccipital muscles and the deep cervical muscles [6], so the purpose of this study was to evaluate the effect of DCFs training on neck proprioception, pain, muscle strength and dizziness in patients with cervical spondylosis.

The results of the current study showed that, DCFs training group had a significant improvement in proprioception than the group received traditional physical therapy. These findings are in agreement with the findings of Jull et al. [11] who mentioned that DCFs training is effective approach for improving proprioception in patients with chronic neck pain. These findings might be explained by several mechanisms. First, The DCFs training directly activates the DCFs [29], and this justification is supported by the findings of O'Leary et al. [30] and Rezasoltani et al. [31] who found that, retraining the DCFs increase the activation of the DCFs during performance of the clinical test of CCF. These DCFs have a relatively high density of muscle spindles, which generally accepted as being the primary cervical receptors responsible for position sense $[4,6]$. Thus, the repeated contractions of DCFs during DCFs training may improve muscle spindle function which translating to improved cervical proprioception.
It has been suggested that abnormal joint stress in patients with cervical spondylosis may alter firing of cervical afferents with resultant changes in proprioceptive function [32]. Thus, the second explanation for the significant improvement of proprioception in study group than control group in the current study might be attributed to improvement of cervical neuromuscular control gained after DCFs training which lead to decrease stresses placed on the joints and other structures of the cervical region $[33,34]$.

The third explanation is using of PBU during DCFs training for the study group. As the PBU provides patients with constant feedback during each repetition of the exercises that encourages patients to perform exercises correctly and gets them more involved in the treatment which augment the patient's sensory feedback mechanisms through precise information about body processes [35].

It has been reported by Jull et al. [10] that, sternocleidomastoid muscle activity is reduced and DCFs activity is increased following DCFs training, as measured with electromyography. So, the fourth explanation may be related to this changes in activity of the deep and superficial muscles, which may alter cervical inter segmental kinematics leading to improved acuity for cervical movement and responsible for changes in 
proprioception. This explanation is supported by the opinion of Proske et al. [36] who mentioned that changes in activity of the deep and superficial muscles may be responsible for changes in proprioception.

Regard to pain intensity, there is a significant improvement in pain intensity level in DCFs groups than control group. This result comes in agreement with the findings of Iqbal et al. [35] and Gupta et al. [37] who mentioned that DCFs training improved chronic neck pain more significantly than conventional physical therapy. While, the result disagrees with the findings of Izquirdo et al. [38] who found that there was no significant difference between DCFs training and conventional proprioceptive training in improving chronic neck pain. This significant decrease in the reported pain is another explanation for the significant improvement of proprioception in DCFs group than traditional physical therapy group. This explanation based on that, pain induces changes in muscle spindle discharge and the proprioceptive properties of brainstem neurons [4].

This significant improvement of pain in DCFs group might be attributed to more significant improvement of DCFs strength as evaluated by the CCFT. This explanation is supported by the opinion of Ylinen et al. [39] who mentioned that weakness of DCFs tend to cause neck pain. Also, it can be confirmed by Javanshir et al. [40] who mentioned that, there is relationship between reduction in strength and endurance capacity of the DCFs and neck pain. Moreover, DCFs training might directly influence pain sensitive structures of upper cervical region more than conventional training [41].

The significant improvement in the strength of DCFs in the study group than the control group in the current study come in agreement with previous observations by Jull et al. [10] who conducted a study to compare between the effect of DCFs training and another therapeutic exercise on activation of DCFs in people with chronic neck pain and they reported that, activation of the DCFs was significantly increased at each of the five levels of the CCFT after CCFs training.

Regarding the severity of dizziness and $\mathrm{DHI}$, the results revealed statistically significant changes favoring the study group. This might be attributed to the reported significant improvement of proprioception and severity of pain in the study group than the control group. This explanation is based on the fact that, neck pain is a cause of dizziness, unsteadiness and altered cervical proprioception $[\mathbf{2 8 , 4 2}]$, and also supported by Clark et al. [43] who stated that, there is a connection between neck pain, cervical proprioceptors and dizziness.

\section{Limitations}

This study has some limitations, however, each of which points toward directions of future study. The primary limitation was the lack of following up the long term effects of DCFs training on proprioception, pain, muscle strength and dizziness in patients with cervical spondylosis, as, the study considered only the immediate effects. In addition, it was not be pos- sible to blind the physiotherapist due to the nature of the interventions which need the direct communication between the physiotherapist and the patients. Furthermore, the initial selection of the patients was represented as a convenient sample rather than a random sample of the whole population.

\section{Conclusions}

The study findings indicate that, DCFs training was more effective, comfortable and safe for improving neck proprioception, severity of pain, DCFs strength, severity of dizziness, and DHI scores. These observed effects should be of value to clinicians and health professionals involved in the treatment of patient with cervical spondylosis.

\section{Competing interests}

The authors declare that they have no competing interests.

Authors' contributions

\begin{tabular}{|l|c|c|c|}
\hline Authors' contributions & MSMS & NIR & MAFS \\
\hline Research concept and design & $\checkmark$ & $\checkmark$ & -- \\
\hline Collection and/or assembly of data & $\checkmark$ & $\checkmark$ & -- \\
\hline Data analysis and interpretation & $\checkmark$ & $\checkmark$ & $\checkmark$ \\
\hline Writing the article & $\checkmark$ & $\checkmark$ & -- \\
\hline Critical revision of the article & $\checkmark$ & $\checkmark$ & $\checkmark$ \\
\hline Final approval of article & $\checkmark$ & $\checkmark$ & $\checkmark$ \\
\hline Statistical analysis & $\checkmark$ & $\checkmark$ & $\checkmark$ \\
\hline
\end{tabular}

\section{Acknowledgement}

Many thanks, to all patients who participated in this study for their co-operation.

\section{Publication history}

Editor: Mohammad H. Hadadzadeh, wheeling Jesuit University, USA. Received: 28-Jun-2018 Final Revised: 07-Aug-2018

Accepted: 29-Aug-2018 Published: 06-Sep-2018

\section{References}

1. Bovim $\mathrm{G}$, Schrader $\mathrm{H}$ and Sand T. Neck pain in the general population. Spine (Phila Pa 1976). 1994; 19:1307-9. | PubMed

2. Yun S, Kim M, Weon J and Kwon O. Effect of cervical corrective exercises on pain, neck posture and intersegmental motion of cervical spine in a patient with cervical radiculopathy: A case report. Phys Ther Korea . 2015; 22:1-7. | Article

3. Wrisley DM, Sparto PJ, Whitney SL and Furman JM. Cervicogenic dizziness: a review of diagnosis and treatment. J Orthop Sports Phys Ther. 2000; 30:755-66. | Article | PubMed

4. Reddy RS. Proprioceptive reposition errors in subjects with cervical spondylosis. International Journal of Health Sciences \& Research. 2012; 1:65-73.

5. Heikkila $\mathrm{H}$ and Astrom PG. Cervicocephalic kinesthetic sensibility in patients with whiplash injury. Scand J Rehabil Med. 1996; 28:133-8. | PubMed

6. Boyd-Clark LC, Briggs CA and Galea MP. Muscle spindle distribution morphology, and density in longus colli and multifidus muscles of the cervical spine. Spine (Phila Pa 1976). 2002; 27:694-701. | Article | PubMed

7. Janda V. Muscles and motor control in cervicogenic disorders: Assessment and management. Physical Therapy of the Cervical and Thoracic Spine. 2 nd ed, Churchill Livingstone, New York. 1994; 195-216.

8. Revel M, Minguet M, Gregoy P, Vaillant J and Manuel JL. Changes in cervicocephalic kinesthesia after a proprioceptive rehabilitation 
Saleh et al, Physical Therapy and Rehabilitation 2018,

program in patients with neck pain: a randomized controlled study. Arch Phys Med Rehabil. 1994; 75:895-9. | PubMed

9. Humphreys B K and Irgens PM. The effect of a rehabilitation exercise program on head repositioning accuracy and reported levels of pain in chronic neck pain subjects. J Whiplash Relat Disord. 2002; 1:99-112. Article

10. Jull GA, Falla D, Vicenzino B and Hodges PW. The effect of therapeutic exercise on activation of the deep cervical flexor muscles in people with chronic neck pain. Man Ther. 2009; 14:696-701. I Article I PubMed

11. Jull G, Falla D, Treleaven J, Hodges P and Vicenzino B. Retraining cervical joint position sense: the effect of two exercise regimes. J Orthop Res. 2007; 25:404-12. | Article | PubMed

12. Falla $D$, Jull $G$ and Hodges P. Training the cervical muscles with prescribed motor tasks does not change muscle activation during a functional activity. Man Ther. 2008; 13:507-12. | Article | PubMed

13. Falla D, Lindstrom R, Rechter L, Boudreau S and Petzke F. Effectiveness of an 8-week exercise programme on pain and specificity of neck muscle activity in patients with chronic neck pain: a randomized controlled study. Eur J Pain. 2013; 17:1517-28. | Article | PubMed

14. Lluch E, Arguisuelas MD, Coloma PS, Palma F, Rey A and Falla D. Effects of deep cervical flexor training on pressure pain thresholds over myofascial trigger points in patients with chronic neck pain. $J$ Manipulative Physiol Ther. 2013; 36:604-11. I Article I PubMed

15. Whitney SL, Wrisley DM, Brown KE and Furman JM. Is perception of handicap related to functional performance in persons with vestibular dysfunction? Otol Neurotol. 2004; 25:139-43. | Article | PubMed

16. Jordan K. Assessment of published reliability studies for cervical spine range-of-motion measurement tools. J Manipulative Physiol Ther. 2000; 23:180-95. | Article | PubMed Abstract | PubMed FullText

17. Tousignant M, Duclos E, Lafleche S, Mayer A, Tousignant-Laflamme $Y$, Brosseau $L$ and O'Sullivan JP. Validity study for the cervical range of motion device used for lateral flexion in patients with neck pain. Spine (Phila Pa 1976). 2002; 27:812-7. | Article | PubMed

18. Reid SA, Rivett DA, Katekar MG and Callister R. Efficacy of manual therapy treatments for people with cervicogenic dizziness and pain: protocol of a randomised controlled trial. BMC Musculoskelet Disord. 2012; 13:201. | Article | PubMed Abstract | PubMed FullText

19. Hawker GA, Mian S, Kendzerska T and French M. Measures of adult pain: Visual Analog Scale for Pain (VAS Pain), Numeric Rating Scale for Pain (NRS Pain), McGill Pain Questionnaire (MPQ), Short-Form McGill Pain Questionnaire (SF-MPQ), Chronic Pain Grade Scale (CPGS), Short Form-36 Bodily Pain Scale (SF-36 BPS), and Measure of Intermittent and Constant Osteoarthritis Pain (ICOAP). Arthritis Care Res (Hoboken). 2011; 63 Suppl 11:S240-52. | Article | PubMed

20. Walton DM, Macdermid JC, Nielson W, Teasell RW, Nailer T and Maheu P. A descriptive study of pressure pain threshold at $\mathbf{2}$ standardized sites in people with acute or subacute neck pain. J Orthop Sports Phys Ther. 2011; 41:651-7. | Article | PubMed

21. Chiu TT, Law EY and Chiu TH. Performance of the craniocervical flexion test in subjects with and without chronic neck pain. J Orthop Sports Phys Ther. 2005; 35:567-71. | Article | PubMed

22. Reid SA, Rivett DA, Katekar MG and Callister R. Sustained natural apophyseal glides (SNAGs) are an effective treatment for cervicogenic dizziness. Man Ther. 2008; 13:357-66. | Article | PubMed

23. Jacobson GP and Newman CW. The development of the Dizziness Handicap Inventory. Arch Otolaryngol Head Neck Surg. 1990; 116:424-7. | Article | PubMed

24. Enloe $L J$ and Shields RK. Evaluation of health-related quality of life in individuals with vestibular disease using disease-specific and general outcome measures. Phys Ther. 1997; 77:890-903. | PubMed

25. Whitney SL, Wrisley DM, Brown KE and Furman JM. Physical therapy for migraine-related vestibulopathy and vestibular dysfunction with history of migraine. Laryngoscope. 2000; 110:1528-34. | Article | PubMed

26. Basford JR. Physical agents. In: DeLisa JA and Gans BM. Rehabilitation medicine: principles and practice. Philadelphia: Lippincott-Raven Publishers 3rd ed. 1998; 483-503.

27. Jull G, Sterling M, Falla D, Treleaven J and O'Leary S. Whiplash, headache, and neck pain: research-based directions for physical therapies: research-based directions for physical therapies Edinburgh. Churchill
Livingstone. 2008. | Website

28. Kristjansson E and Treleaven J. Sensorimotor function and dizziness in neck pain: implications for assessment and management. J Orthop Sports Phys Ther. 2009; 39:364-77. | Article I PubMed

29. Falla D, Jull G, Dall'Alba P, Rainoldi A and Merletti R. An electromyographic analysis of the deep cervical flexor muscles in performance of craniocervical flexion. Phys Ther. 2003; 83:899-906. PubMed

30. O'Leary S, Jull G, Kim M and Vicenzino B. Specificity in retraining craniocervical flexor muscle performance. J Orthop Sports Phys Ther. 2007; 37:3-9. | Article | PubMed

31. Rezasoltani A, Khaleghifar M, Tavakoli A and Minoonegad H. The effect of a proprioceptive neuromuscular facilitation program to increase neck muscle strength in patients with chronic non-specific neck pain. World Journal of Sport Sci. 2010; 3:59-63.

32. Taylor JL and McCloskey DI. Illusions of head and visual target displacement induced by vibration of neck muscles. Brain. 1991; 114 ( Pt 2):755-9. | PubMed

33. Mayoux-Benhamou MA, Revel M, Vallee C, Roudier R, Barbet JP and Bargy F. Longus colli has a postural function on cervical curvature. Surg Radiol Anat. 1994; 16:367-71. I PubMed

34. Panjabi MM, Cholewicki J, Nibu K, Grauer J, Babat LB and Dvorak J. Critical load of the human cervical spine: an in vitro experimental study. Clin Biomech (Bristol, Avon). 1998; 13:11-17. | Article | PubMed

35. Iqbal ZA, Rajan R, Khan SA and Alghadir AH. Effect of deep cervical flexor muscles training using pressure biofeedback on pain and disability of school teachers with neck pain. J Phys Ther Sci. 2013; 25:657-61. | Article | PubMed Abstract | PubMed FullText

36. Proske $U$, Wise AK and Gregory JE. The role of muscle receptors in the detection of movements. Prog Neurobiol. 2000; 60:85-96. | Article | PubMed

37. Gupta BD, Aggarwal S, Gupta B, Gupta M and Gupta N. Effect of Deep Cervical Flexor Training vs. Conventional Isometric Training on Forward Head Posture, Pain, Neck Disability Index In Dentists Suffering from Chronic Neck Pain. J Clin Diagn Res. 2013; 7:2261-4. I Article I PubMed Abstract I PubMed FullText

38. Gallego Izquierdo T, Pecos-Martin D, Lluch Girbes E, Plaza-Manzano G, Rodriguez Caldentey R, Mayor Melus R, Blanco Mariscal D and Falla D. Comparison of cranio-cervical flexion training versus cervical proprioception training in patients with chronic neck pain: $\mathrm{A}$ randomized controlled clinical trial. J Rehabil Med. 2016; 48:48-55. | Article I PubMed

39. Ylinen J, Salo P, Nykanen M, Kautiainen H and Hakkinen A. Decreased isometric neck strength in women with chronic neck pain and the repeatability of neck strength measurements. Arch Phys Med Rehabil. 2004; 85:1303-8. | Article | PubMed

40. Javanshir K, Mohseni-Bandpei MA, Rezasoltani A, Amiri M and Rahgozar M. Ultrasonography of longus colli muscle: A reliability study on healthy subjects and patients with chronic neck pain. J Bodyw Mov Ther. 2011; 15:50-6. | Article | PubMed

41. O'Leary S, Falla D, Hodges PW, Jull G and Vicenzino B. Specific therapeutic exercise of the neck induces immediate local hypoalgesia. $J$ Pain. 2007; 8:832-9. | Article I PubMed

42. Treleaven J, Chen X and Sarig Bahat H. Factors associated with cervical kinematic impairments in patients with neck pain. Man Ther. 2016; 22:109-15. | Article | PubMed

43. Clark NC, Roijezon U and Treleaven J. Proprioception in musculoskeletal rehabilitation. Part 2: Clinical assessment and intervention. Man Ther. 2015; 20:378-87. | Article | PubMed

\section{Citation:}

Saleh MSM, Rehab NI and Sharaf MAF. Effect of deep cervical flexors training on neck proprioception, pain, muscle strength and dizziness in patients with cervical spondylosis: A randomized controlled trial. Phys Ther Rehabil. 2018; 5:14.

http://dx.doi.org/10.7243/2055-2386-5-14 